\title{
A ATLÂNTIDA E OS CICLOS EM VICO
}

\author{
Vladimir Chaves dos Santos*
}

\section{RESUMO}

A teoria cíclica da história tem muitas variantes. Em Vico, a teoria cíclica é adaptada a uma teoria do progresso. Platão e Políbio apresentam teorias cíclicas diferentes, que são referência para a teoria da história de Vico. Platão é uma das fontes declaradas para a reflexão sobre os primeiros tempos. Políbio é importante para a explicação das causas humanas que concorrem para o fenômeno da recorrência na história.

PALAVRAS-CHAVE: Giambattista Vico. História. Ciência.

\begin{abstract}
The cyclical theory of history has many variants. In Vico, the cyclical theory is adapted to a theory of progress. Plato and Polybe present different cyclical theories, and both are reference to the Vico's theory of the history. Plato is one of the sources declared for reflection on the early times. Polybe is important for explaining the human causes contributing to the advent of recurrence in history.
\end{abstract}

KEYWORDS: Giambattista Vico. History. Science.

Parece razoável começar um debate sobre filosofia da história a partir do confronto entre uma concepção cíclica e uma concepção retilínea de história: a primeira teria como fundamento a ideia de eterno retorno e a segunda a ideia de peregrinação e progresso; aquela seria oriunda da antiguidade clássica, essa adviria da tradição judaico-cristã, mas teria

* Doutor em Filosofia pela UNICAMP e Professor Adjunto do Departamento de Filosofia da Universidade Estadual de Maringá (UEM). E-mail: vlasanto@terra.com.br 
adquirido seus traços mais definidos e seu aparato teórico no Iluminismo; aquela implicaria um tempo infinito, eterno; essa um tempo finito, no qual a história se desenrola como uma peregrinação em linha reta desde a Criação até o Juízo Final. Todas as perspectivas sobre o sentido da história, principalmente no século XVIII, podem então ser enquadradas no âmbito da tensão entre esses dois modelos. Voltaire, em uma espécie de "otimismo realista", aposta no progresso, mas mantém a concepção cíclica para dar conta dos períodos em que a humanidade entra em decadência. Rousseau, ao contrário, afirma o aspecto acumulativo linear, porém de uma história decadente, e toma da concepção cíclica justamente o pessimismo. Kant, ao defender a ideia do Esclarecimento como progresso contínuo e indefinido, funde a ideia da linearidade acumulativa do progresso com a ideia de tempo infinito. O Iluminismo seria, então, uma filosofia do progresso, em cuja perspectiva a concepção linear da história suplanta a cíclica. ${ }^{1}$

Não é preciso dizer que as noções de teoria cíclica e teoria do progresso são genéricas e uniformizam uma pletora de concepções sobre o sentido da história. Tampouco se pode dizer que na antiguidade clássica só é possível encontrar a percepção do cíclico. ${ }^{2}$ No que concerne à teoria cíclica, a essa vem associadas a ideia do eterno retorno, a concepção da idade de ouro como localizada no passado e do tempo como um elemento destruidor e corruptor. ${ }^{3}$ Entretanto, é possível pensar em noções de ciclos diferentes, sem essas determinações, mesmo na antiguidade. A ideia do eterno retorno, por exemplo, é ambígua, pois há uma grande diferença entre o retorno do mesmo e o retorno do semelhante. Numa cultura originariamente agrícola, como é a grega - levando-se em consideração que Gaia, para os gregos, é a mãe de todos -, a noção de tempo nasce evidentemente da própria observação do clima e dos astros. É nesse

${ }^{1}$ Terra, R. Algumas Questões sobre a filosofia da história em Kant. In: KANT. Ideia de uma história universal de um ponto de vista cosmopolita, Brasiliense, 1986, p. 41, $52-54,58,60$. Um estudo amplo sobre a teoria cíclica e a teoria do progresso é o de Löwith, K. Significato e fine della storia, Comunità, 1979.

${ }^{2}$ Algumas passagens descritivas do progresso humano entre os gregos encontram-se em Guthrie, W.K.C. Os Sofistas, Paulus, 2007, p. 78-82.

${ }^{3}$ Terra, R. Algumas Questões sobre a filosofia da história em Kant. In: KANT. Ideia de uma história universal de um ponto de vista cosmopolita, p. 44-45, 47, 52. 
sentido que as noções de eterno retorno e de tempo cíclico parecem ser primeiramente percebidas pelo imaginário dos gregos antigos. O que parece ser um lugar comum no pensamento grego antigo não é, porém, o eterno retorno do mesmo, como no suplício de Sísifo, com forma de círculo fechado, mas o eterno retorno do semelhante, um tempo em que ocorre o retorno de momentos semelhantes, jamais idênticos. As ideias do tempo como um elemento destruidor e da história como decadência a partir de uma idade de ouro localizada no passado encontram-se em $O s$ trabalhos e os Dias de Hesíodo. Aí, vê-se a história humana caminhando do melhor para o pior, decaindo a partir da idade de ouro; se bem que há um momento positivo de melhoramento constituído pela idade dos heróis, a qual recai novamente na decadência com a última idade, a de ferro, que é a do próprio Hesíodo. O deus do tempo, Chronos, apresentado na Teogonia, tem esse caráter destruidor, pois devora os filhos. Nesse sentido, opõe-se ao futuro. Todavia, em seguida, ele é superado pelo filho, Zeus. A história dos deuses, na Teogonia, recebe um sentido bem diferente daquele da história dos homens. Há três ciclos: Urano, Chronos e Zeus, sucessivamente, e a passagem de um para outro se dá pela superação. Portanto, há mais razões para se supor que há um progresso na história dos deuses do que uma decadência. De fato, na própria Teogonia, Zeus passa a saber que um filho seu estava destinado a superá-lo, ameaça que aparece novamente na tragédia de Ésquilo, Prometeu Acorrentado. Assim, em Hesíodo a noção de história cíclica não implica apenas as ideias de tempo negativo e de decadência: progresso entre os deuses e decadência entre os homens. ${ }^{4} \mathrm{O}$ mesmo acontece naquela formulação lapidar da ideia do ciclo, a sentença de Anaximandro. ${ }^{5}$ Nessa, encontra-se um tempo infinito, e não só destrutivo, mas também produtivo.

O mito da Atlântida de Platão, entre outras coisas, pode ser visto

\footnotetext{
${ }^{4}$ Hesíodo. Teogonia, Iluminuras, 1992, verso 459, 896; idem, Os trabalhos e os dias, Iluminuras, 1996.

5 Pré- Socráticos. Anaximandro. In: Os Pensadores, Abril, 1978, tradução de José Cavalcante de Souza. p. 17. "Princípio dos seres... ele disse (que era) o ilimitado... Pois donde a geração é para os seres, é para onde também a corrupção se gera segundo o necessário; pois concedem eles mesmos justiça e deferência uns aos outros pela injustiça, segundo a ordenação do tempo."
} 
como um capítulo importante acerca da teoria de história e do sentido do tempo. As noções de tempo e de história entre os gregos são profusas. O lugar comum da concepção de história cíclica que é atribuído a toda antiguidade clássica tem, na verdade, traços notadamente platônicos. É em Platão que se encontram todos aqueles elementos: o tempo pode ser dito negativo, ${ }^{6}$ infinito, e a história pode ser vista como cíclica e repetitiva. ${ }^{7}$ Cabe, nesse ponto, um estudo mais detido sobre dois momentos capitais para a formação da filosofia da história de Platão: de um lado, os diálogos Timeu e Crítias, de outro lado, As Leis.

O primeiro momento consiste no grandioso e enigmático mito da Atlântida. Os primeiros registros desse mito estão em Platão, no prólogo do diálogo Timeu e ao longo do que resta do Crítias. Sua grandiosidade deve-se ao fato desse mito ter influenciado, desde a Idade Média, as mais diversas nações na construção de suas genealogias e seus mitos nacionais, sendo frequentemente fundido a elementos cristãos. $^{8} \mathrm{O}$ enigma não é outro senão saber se se trata de um mito ou de uma história verídica. Assim como as genealogias e os mitos nacionais pretendem ser verídicos,

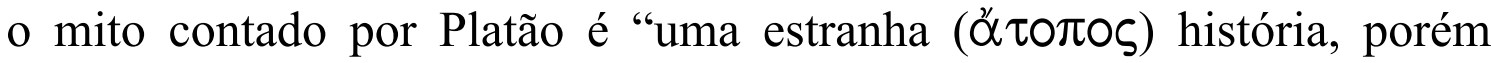
absolutamente verdadeira, pelo que uma vez dissera Sólon, o mais sábio dos sete sábios." Destoa de todos os mitos contidos nos demais diálogos platônicos, e sequer é apresentado como mito: não se trata de uma história mítica, oriunda da oralidade, como toda a mitologia grega que aos olhos de Platão é considerada infantil, ${ }^{10}$ mas de uma história escrita e registrada em números precisos, fruto de uma pesquisa ( $\alpha \nu \alpha \zeta \eta ் \eta \eta \sigma \iota)$ histórica, que "não surge nos Estados senão com o lazer e quando certos cidadãos constatam que já reuniram tudo que é necessário à vida.". ${ }^{11}$ Esse Estado

${ }^{6}$ Platone. "Timeo”, in Tutte le opere, Grandi Tascabili Economici Newton, 1997, 22c, p. 544-545.

${ }^{7}$ Idem. "Leggi", in Tutte le opere, Grandi Tascabili Economici Newton, 1997, 677c, p. 140-141.

${ }^{8}$ Vidal-Naquet, P. La Démocratie Grecque vue d'ailleurs. Flammarion, 1990. p. 143.

${ }^{9}$ Platone. "Timeo", 20e, p. 542-543.

${ }^{10}$ Ibidem, 23b. p. 546-547.

${ }^{11}$ Idem. "Crizia", in Tutte le opere, Grandi Tascabili Economici Newton, 1997, 110a. p. 666-9; cf. idem. "Timeo", 23a. p. 546-547. 
é o Egito, onde se guardam os mais remotos registros escritos da história, pois, devido à privilegiada posição geográfica do Nilo, estão protegidos das periódicas catástrofes naturais que levam tudo o que a humanidade acumulara até então. ${ }^{12} \mathrm{~A}$ história contada por um sacerdote egípcio, que se ampara nos registros escritos, pode ser vista como um romance histórico e como tal é situada no tempo e no espaço ${ }^{13}$. Tempo: 9.000 anos antes de Sólon. Contudo, é a referência espacial que fascina: ao situar a ilha da Atlântida no meio do grande oceano, o relato afirma que dessa ilha se

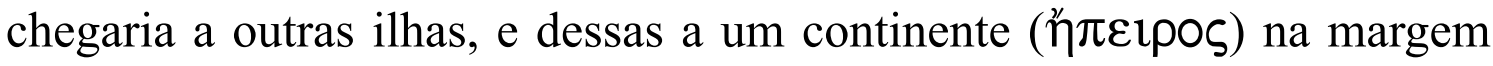
oposta do grande oceano! ${ }^{14}$

Em Platão, encontra-se a ideia de que a história não é acumulativa: "Os homens foram destruídos, e o serão ainda, de muitas maneiras, pelo fogo e pela água; tiveram lugar as destruições mais graves, mas as houve menores, de mil outras maneiras.". ${ }^{15}$ Entretanto, nem sempre o acúmulo é negado ao homem. Em lugares a salvo das catástrofes naturais onde haja a escrita desde os mais remotos tempos, como no Egito, será possível guardar a memória de tudo que tenha sido bom, grande ou notável. ${ }^{16}$ Desse modo, o próprio conhecimento histórico aparece como meio para romper os ciclos de destruição na história; Em contrapartida, a sociedade que não tem história fica submetida ao círculo infernal do eterno esquecimento. Fica claro no texto platônico a consideração do valor da história. Uma sociedade sem história é análoga a uma criança, pois não tem uma opinião antiga nem um conhecimento $(\mu \alpha \dot{\theta} \theta \eta \mu \alpha)$ encanecido pelo tempo. ${ }^{17}$

Quando o sacerdote egípcio declara que os gregos são eternas crianças, ${ }^{18}$ percebe-se, no fundo, uma crítica platônica dirigida à sociedade de seu tempo. Lembre-se o papel metafórico que a criança tem nas obras platônicas, toda sua carga negativa está expresso nessa exclamação do

\footnotetext{
${ }^{12}$ Idem. "Timeo", 22d, p. 544-7.

${ }^{13}$ Vidal-Naquet, P. La Démocratie Grecque vue d'ailleurs. p. 140.

${ }^{14}$ Platone. "Timeo", 25a, p. 548-549.

${ }^{15}$ Ibidem, 22c, p. 544-545.

${ }^{16}$ Ibidem, 23a. p. 546-547.

${ }^{17}$ Ibidem, 22b, p. 544-545.

${ }^{18}$ Ibidem.
} 
sacerdote. No diálogo Górgias, a multidão que aprecia o agradável e prefere o retórico-demagogo ao filósofo é comparada a um tribunal de crianças, perante as quais um cozinheiro e um médico discutiriam qual dos dois entenderia melhor de bons e maus alimentos - o "povo-criança", na realidade, prefere o cozinheiro ao médico, o qual seria condenado, ${ }^{19}$ assim como foi o filósofo Sócrates. A identificação com a criança está associada à ignorância:

Entretanto, entre vós e entre outros povos, cada vez que tudo se encontra um tanto organizado, no que tange à escrita, e o mais que é necessário à civilização, eis que de novo, a intervalos regulares como uma doença, as águas do céu recaem sobre vós e só deixam sobreviver iletrados e ignorantes. Assim, novamente vos tornais jovens, sem nada saber do que ocorreu aqui, nem convosco, nos tempos antigos. 20

A ignorância em relação ao passado coletivo é um fator de desunião, típica de uma sociedade na qual os indivíduos apenas tem olhos para si mesmos e o espírito voltado para a satisfação das necessidades presentes, ${ }^{21}$ no caso, uma referência à democracia daqueles tempos, que, aos olhos de Platão, vivia sob a égide do individualismo e do hedonismo. A existência do conhecimento histórico é um sinal de união e ao mesmo tempo um sinal de desenvolvimento. A história enquanto conhecimento $(\mu \alpha \dot{\theta} \theta \eta \mu \alpha)$ tem uma história recente, apenas viceja em cidades maduras, e o esquecimento da história é sinal de uma sociedade individualista e imatura. Certamente Platão está decepcionado com a realidade política e a sociedade atenienses, onde impera o individualismo e uma falta de patriotismo e memória política em função da repetição de erros do passado.

Platão estabelece um confronto entre a história, enquanto ciência, e a mitologia. A oralidade e a mitologia são vistas negativamente, uma vez que são incapazes de registrar o que "verdadeiramente" ocorreu no passado. Desse modo, mostram-se inconsistentes para sustentar um "verdadeiro"

\footnotetext{
${ }^{19}$ Idem. "Gorgia", 464d, 502e, 521e. p. 380-381, 458-459, 492-493.

${ }^{20}$ Idem. "Timeo", 23a. p. 546-547.

${ }^{21}$ Idem. "Crizia", 110a. p. 666-667.
} 
patriotismo. Esse somente ganha sentido com uma ciência da história, tal como Platão a apresenta, com datas e nomes exatos, uma geografia precisa e, o mais importante, o recurso da escrita. Essa é estimada como um remédio para a memória, e a mitologia, fruto de uma tradição oral, é tão imprecisa nas suas referências de tempo e espaço, omitindo vários eventos ou superpondo-os, que mais parece uma série de contos infantis, insuficientes para guardar a memória do passado. As raízes culturais tornamse obscuras, porque os sobreviventes das catástrofes e seus descendentes ao longo de várias gerações morrem sem ter sido capazes de se exprimir por escrito, ${ }^{22}$ iletrados que são.

Uma ciência da história, ${ }^{23}$ calcada em dados precisos, ou seja, em documentos escritos e não em mitologias, condiz com a exigência de precisão que é requerida para o tratamento das coisas humanas. Com efeito, "se se tratam de coisas celestes e divinas, estamos satisfeitos, mesmo se o que se diz só tem pequena semelhança com elas. Mas, para as coisas mortais e humanas, submetemo-la a uma crítica cerrada.". ${ }^{24}$ Isso significa que a história é o objeto mais próprio do saber humano, porque é mais próxima e porque temos mais autoridade para julgá-la. Nesse sentido, entende-se o pedido de indulgência de Crítias para com a sua história. A precisão é mais facilmente forjável e aceita nas ciências naturais do que na história, pois os homens são mais exigentes com essa, mais familiar do que aquela.

O pedido de indulgência de Crítias é inspirador, sobretudo pela conclusão de Vico: de que os critérios de verdade para a história devem ser distintos daqueles das ciências naturais. Descartes retira a história do rol das ciências, devido à incapacidade de se alcançar certezas na história; apenas a certeza cujo modelo é a matemática, seria condição de cientificidade. A história é vista como um aglomerado de fatos desconexos, e seu estudo não resulta em nenhum conhecimento prático, além de preconceitos e crenças

${ }^{22}$ Idem. "Timeo", 23c. p. 546-547.

${ }^{23}$ Cumpre advertir que a "história" em Platão não se reduz à "memória", mas envolve também um conceito de tempo e uma teoria cíclica, isto é, uma teoria sobre os movimentos e os processos históricos, como se nota, por exemplo, no livro VIII da República e no livro III das Leis.

${ }^{24}$ Idem. "Crizia", 107d. p. 662-665. 
mal fundadas. Descartes reage contra o humanismo na mesma medida em que celebra a vitória das ciências naturais sobre as humanidades. As ciências naturais, para Descartes, são mais apropriadas às condições da razão humana. Entretanto, para Vico, o homem somente conhece aquilo que ele mesmo faz. ${ }^{25}$ Para a razão finita, como é a do homem, não é dado o conhecimento pleno das coisas naturais, pois não foi ele quem as fez; apenas a Deus, criador da natureza, isso é possível; aos homens é lícito conhecê-las apenas superficialmente. Em contrapartida, a história do mundo civil é feita pelo próprio homem, e, por isso, ele pode conhecê-la plenamente, sendo o objeto mais próprio para o conhecimento humano. ${ }^{26}$ A fim de restabelecer a história como ciência, Vico, então, abandona o modelo científico cartesiano e resgata parâmetros da antiga tradição da retórica: ao invés da razão lógico-matemática, é à razão engenhosa que se vale da tópica que Vico oferece a posição de verdadeira faculdade do conhecimento, ${ }^{27}$ desse modo, juntamente com a verdade, também o verossímil é válido para essa "nova ciência".

Segundo Vidal Naquet, a história da Atlântida contém o sentido essencial de que a Atlântida e a proto-Atenas são duas faces da Atenas de Platão. A Atenas primordial segue o modelo da cidade justa da República. A Atlântida já corrompida é uma cidade como a Atenas de Péricles e de Cleon, uma potência imperialista e marítima, cuja existência mesma era uma ameaça para as cidades gregas. ${ }^{28} \mathrm{Um}$ reino do mar e um reino do mal são duas noções vizinhas em Platão. ${ }^{29}$ A Atlântida é naturalmente uma potência imperial que, apesar de vir do Oeste, não evoca menos a Pérsia das guerras médicas. A cidade de Atenas recebera sua semente de Gaia e Hefestos, a Atlântida fora criada por Poseidon. Isso representa um confronto entre uma cultura agrária e outra marítimo-mercantil; e não há dúvidas de que Platão preferia a primeira. No caso de Vico, é de se notar a

${ }_{25}$ Vico, G. "De Antiquissima Italorum Sapientia", in Opere Filosofiche, Firenze, Sansoni, 1971. p. 62-63.

${ }^{26}$ Idem. Princìi di Scienza Nuova, Mondadori, Milano, 1992, § 331. p. 121.

${ }^{27}$ Idem. "De Antiquissima Italorum Sapientia". p. 118-125.

${ }^{28}$ Vidal-Naquet, P. La Démocratie Grecque vue d'ailleurs. p. 140.

${ }^{29}$ Ibidem, p. 139. 
oposição entre o arado e o timão na alegoria da Scienza Nuova: um, fonte da civilização, símbolo dos primeiros pais de família, que exercem um domínio ferrenho das terras; o outro, instrumento dos fâmulos amotinados, que não suportam o domínio daqueles e que, vencidos nos primeiros conflitos agrários da história, emigram e dão origem às assim chamadas colônias heróicas ultramarinas. ${ }^{30}$ Há muitas semelhanças entre a Atlântida de Platão e o antigo império micênico, cuja maior fonte de riquezas fora o comércio marítimo. A tauromaquia, que era um costume conhecido dos antigos micênicos, tem um correlato entre os costumes dos reis atlantes descritos por Platão. ${ }^{31}$

Com a história da Atlântida, Platão cumpre a exigência de forjar uma origem autóctone para a cidade idealizada na República, não sob a forma de mito, uma "nobre mentira", mas de uma "história"; o propósito seria incutir uma estima em relação à cidade natal. ${ }^{32}$ Seria um meio de unificação social através da história: a coisa pública se valoriza na medida em que a história da cidade natal, que é um patrimônio coletivo, é valorizada. Sem dúvida, é a expressão de um patriotismo que cria seus mitos para glorificar seu ideal de nação: "A melhor e mais bela raça dentre os homens, não sabeis que foi em vosso país que nasceu, nem que desses homens vós e toda vossa cidade atual descendeis, pois um pouco de sua semente conservou-se." ${ }^{33} \mathrm{O}$ caráter de mito não depende apenas do fato da história da cidade de Atenas ser posta a rodar pelas mãos de Gaia, Hefestos e Atenas, o que seria um aspecto interno ao texto. Há um outro aspecto: o fato dessa história ser um instrumento "ideológico" a serviço de um patriotismo com interesses políticos; isso também reforça o caráter de mito. Esse procedimento foi imitado ao longo de toda história pelas mais

${ }^{30}$ Vico, G. Princìi di Scienza Nuova, § 14-20. Cabe notar que Vico estabelece uma relação de parentesco entre os bestioni, homens selvagens e insociáveis, promotores com seu errar ferino das primeiras transmigrações dos povos por terra, e os fâmulos amotinados, bandos de homens já humanizados pela religião que propagam o gênero humano também por mar; cf. $\S 17$ e 20.

${ }^{31}$ Platone. "Crizia", 119d. p. 684-685.

${ }^{32}$ Plato. The Republic of Plato, Cambridge, 1979, with critical notes, commentary and appendices by James Adam, 382d, 414c-415d. p. 123, 193-197.

${ }^{33}$ Platone. "Timeo", 23c. p. 546-547. 
diversas nações, que, ao buscarem suas origens históricas, frequentemente justificavam o status quo do presente. As aristocracias e as famílias reais sempre buscaram ter suas próprias genealogias. ${ }^{34}$ Por longo tempo, os arquivos históricos serviram como instrumento do governo. ${ }^{35} \mathrm{~A}$ tendência natural aos ideólogos das diversas nações era evidentemente propor sua própria língua como primordial. Segundo Vidal Naquet, o mito da Atlântida serviu de modelo para a criação de vários mitos nacionais europeus, desde a Idade Média, servindo aos mais diversos interesses. Uma das formulações mais claras disso, que se pode chamar de atlantonacionalismo, foi dada em 1572 por Pedro Sarmiento, historiador real, apenas para o proveito do rei espanhol Felipe II. Como a Atlântida, segundo a descrição de Platão, situava-se vizinha às "colunas de Héracles", isto é, à Espanha, seus restos longínquos, a América, deveriam pertencer por direito divino à coroa espanhola! ${ }^{36}$ Vico, quando escreve seu primeiro livro, De Antiquissima Italorum Sapientia (1710), também se vê tentado pelo ufanismo, mas depois, na Scienza Nuova, ele muda o tom: as nações são iguais face a Deus e ao ciclo histórico. ${ }^{37}$

Todavia, o mito da Atlântida é a expressão de um patriotismo amargo. Platão estava profundamente decepcionado com a realidade política de sua época. Por isso, ele a situa muito longe do ideal, como se dissesse: "Estamos longe do ideal". Além disso, a estima em relação à cidade enfraquece na medida em que sua história é esquecida. Tudo está perdido em algum lugar do passado. $\mathrm{O}$ mito da Atlântida representa a fusão de uma concepção cíclica com a concepção da idade de ouro situada no passado e a concepção de tempo como elemento corruptor, cujo resultado é uma visão bastante pessimista da história. Portanto, a política seria um esforço para deter o tempo e quebrar os ciclos de corrupção dos modelos políticos; seria a política da reação contra a corrupção. Nisso, a história se consagra. É preciso voltar ao passado, em busca de uma unidade social perdida, em busca do amor à pátria. Deve-se olhar novamente para Sólon

\footnotetext{
${ }^{34}$ Vidal-Naquet, P. La Démocratie Grecque vue d'ailleurs. p. 144.

${ }^{35}$ Ibidem, p. 142.

${ }^{36}$ Ibidem. p. 150.

${ }^{37}$ Ibidem. p. 154.
} 
e para as primeiras leis da constituição de Atenas, e buscar aí motivos de um patriotismo perdido.

Um outro momento da filosofia da história em Platão dá-se com o terceiro livro das Leis. Nesse diálogo, encontra-se a mesma concepção cíclica do mito da Atlântida. ${ }^{38} \mathrm{E}$ a ideia de repetição aparece de maneira mais incisiva, ainda que não em forma de afirmação, mas em forma de pergunta: "Se tudo se houvesse conservado no estado em que presentemente está, como seria possível inventar algo novo?". ${ }^{39}$ Entretanto, ao contrário do mito da Atlântida, o ideal não é posto num passado inatingível, anterior ao dilúvio. Platão abandona o mito e faz uma verdadeira descrição histórica, tomando como ponto de partida o dilúvio. A função da história em relação à cidade ideal toma nas Leis rumos bem diferentes. A história da cidade ideal forjada na República não interfere e é posterior à sua elaboração, e tem a função pessimista de mostrar o quanto os gregos estavam distantes do ideal. Nas Leis abre-se uma outra perspectiva em relação ao futuro. A história fundamenta à concepção da cidade ideal, que está por se construir, e serve como repertório que subsidia a sua construção.

As decepções com o projeto de rei-filósofo em Siracusa fazem Platão voltar suas atenções novamente para sua cidade natal. Seu projeto de reforma política, por fim, pretende ser possível em Atenas. Um balanço histórico capacita o político a encontrar modelos que servem de norma para a construção de uma cidade ideal historicamente possível. Nas Leis, encontram-se alguns sinais dessa perspectiva para o futuro, tendo ainda como modelo a constituição espartana: "Alguma divindade que se interessava por vós (espartanos) e prevendo as coisas futuras gerou um duplo ramo de uma só estirpe, reduzindo-a assim à justa medida.". ${ }^{40}$ Nas Leis, a relação entre história e política ganha laços fortes; é necessário buscar no passado modelos políticos. Compare-se, por exemplo, com o procedimento de Maquiavel em O Príncipe, esta passagem: "Vamos ver o que era bom ou mau em seus fundamentos, que leis mantiveram de pé o que se conservou, ou fizeram perecer o que veio a desaparecer, e com que mudanças ou substituições

\footnotetext{
${ }^{38}$ Platone. "Leggi”, 676b-677a, p. 138-139.

${ }^{39}$ Ibidem. 677c. p. 140-141.

${ }^{40}$ Ibidem, 691e. p. 166-167.
} 
conseguiríamos deixar feliz uma cidade.". ${ }^{41} \mathrm{O}$ espírito patriótico, antes perdido indefinidamente, é referido como causa da não destruição dos helenos pelos Persas. ${ }^{42}$ Nas Leis, o patriotismo toma a forma de respeito à antiguidade das leis, e desaparece o mito da origem autóctone.

As afinidades desse terceiro livro das Leis com a Scienza Nuova de Vico são muitas. Vico praticamente segue os mesmos passos de Platão no que tange à descrição dos primórdios do processo civilizatório. Ambos começam suas histórias pelo dilúvio. E Vico tem motivos religiosos para começar desse ponto: ele não pretende entrar em conflito com a história sagrada, de tal maneira que, a partir do dilúvio, sai da história sacra com a história dos gentis, servindo-se então de várias outras fontes, além da Bíblia. Em Platão, o dilúvio é um marco histórico recorrente. ${ }^{43}$ Há fortes indícios de que Platão encontrou referências ao dilúvio entre os egípcios. A história da Atlântida, que seria uma pré-diluviana, é relatada por um sacerdote egípcio que relembra o dilúvio, suscitado por Sólon, após esse ter contado o mito grego de Deucalião e Pirra, ${ }^{44}$ o qual, por sua vez, tem semelhança com a história de Noé: ambos, Deucalião e Noé, enfrentaram o dilúvio servindo-se de uma grande arca de madeira.

Nas Leis e na Scienza Nuova, o dilúvio não é menos importante como marco espacial do que como marco temporal; isto é, por força dele é determinado o espaço a partir do qual os homens realizam o processo histórico que culmina na civilização: trata-se da descida humana das montanhas à planície. Nas Leis, Platão levanta a hipótese de que as cidades que estavam nas planícies teriam sido totalmente destruídas pelo dilúvio, restando apenas homens habitantes das montanhas, que ignoram as coisas das cidades e que, portanto, não conservam delas nenhuma lembrança; os homens que escaparam do dilúvio deviam ter vivido mais ou menos como pastores das montanhas. Tais homens desconhecem não apenas as artes, o que seria um fato negativo, como também - evocando o aspecto moralmente positivo da ingenuidade e da inocência - os mecanismos da

\footnotetext{
${ }^{41}$ Ibidem, 683b. p. 150-151.

${ }^{42}$ Ibidem, 698b. p. 178-181.

${ }^{43}$ Ibidem, 677a. p. 138-139.

${ }^{44}$ Idem, "Timeo", 22a. p. 544-545.
} 
ambição e da avareza, e ignoram todos os malefícios que eles próprios podem causar uns aos outros. Com o andar do tempo e a multiplicação de nossa espécie, os homens baixam das montanhas para o sopé, ainda com medo das águas. As discórdias e guerras não ocorrem naquele tempo: a princípio por causa do isolamento e também porque não precisam lutar para adquirir alimento. O domínio do fogo e a tecelagem são as únicas artes que os homens das montanhas conservam ${ }^{45}$ (implicitamente, Platão faz uma interpretação histórica do mito de Hefesto e Atenas, deuses que acompanham os atenienses desde seu nascimento, de acordo com a história da Atlântida). Além disso, não há pobreza, nem riqueza, de modo que os costumes são naturalmente nobres. São virtuosos pela sua simplicidade, e, não sendo perspicazes para suspeitar da mentira, aceitam tudo como verdade. Vico chama a atenção para o fato de que a ironia, o jogo entre mentira e veracidade, só é possível em tempos avançados nos quais já se encontra desenvolvida a capacidade reflexiva da razão. ${ }^{46}$ Os primitivos de Platão não conhecem a escrita e não necessitam de legislador nem de leis; vivem sob a autoridade patriarcal. Para caracterizar esses primeiros homens, Platão recorre à imagem dos ciclopes de Homero:

Para eles não há ágora deliberante, nem leis

O cimo de altas montanhas, eles habitam

Em grutas escavadas, e cada um dita a lei

A seus filhos e mulheres, sem darem notícias uns aos outros ${ }^{47}$

Platão entende que o mito dos ciclopes é um testemunho mítico de uma forma rude ( $\alpha \gamma \gamma$ pló $\tau\rceil \alpha)$ e primitiva de governo $(\pi \circ \lambda \imath \tau \varepsilon \dot{\imath} \alpha),{ }^{48}$ isto é, de organização social. Nessa passagem Platão não poupa elogios a Homero por seu testemunho histórico - um juízo que incrementa a controversa "expulsão dos poetas". Não se pode deixar de lembrar que no

\footnotetext{
${ }^{45}$ Idem. "Leggi", 679a. p. 142-143.

${ }^{46}$ Vico, G. Principi di Scienza Nuova, § 408.

${ }^{47}$ Platone. "Leggi”, 680b. p. 144-145; cf. Homero. Odisséia, L\&PM, 2007, v. II, IX, 111-115.

${ }^{48}$ Ibidem, 680d. p. 146-147.
} 
Timeu e no Crítias a mitologia não satisfaz as condições para servir como fonte histórica.

Já em maior número, os núcleos familiares reúnem-se em um lugar comum, formando povoados maiores, e se aplicam à agricultura no sopé das montanhas. Contra as feras, levantam sebes de espinho e constroem uma só casa para todos, de grandes proporções. Faz-se necessário escolher entre os grupos um representante para examinar os usos e costumes das famílias, selecionar os que mais lhe agradem e ditá-los aos chefes das famílias. A partir dos conflitos das famílias, em razão de cada uma preferir, em face de outros, os seus costumes particulares que são passados de pai para filho, surge a necessidade de haver uma constituição. Passam, então, das dinastias patriarcais para uma espécie de aristocracia ( $\alpha \rho \imath \sigma \tau о \kappa \rho \alpha \tau i \alpha)$ ou realeza $\left(\beta \alpha \sigma \imath \lambda \varepsilon^{\prime \prime} \alpha\right) .{ }^{49}$

Vico parece ter sempre em seu horizonte a descrição platônica da passagem que vai desde a formação das famílias até a da aristocracia, contida nas Leis. ${ }^{50}$ Ainda assim, ele traz inovações à pesquisa daqueles tempos obscuros. A fase inicial da história é bestial, e nela os homens hostis como animais ferozes vivem solitariamente, sem conúbios certos; até mesmo a família, essa primeira forma de vida em comum, não chega a se constituir. Devido a seu caráter associal, o homem torna-se soberano na solidão, exercendo uma autoridade monástica. De acordo com Vico, a humanidade não passa diretamente do estado bestial para o das "repúblicas", como ocorreria para Hobbes. Vico postula uma fase intermediária, marcada pelo sentimento religioso de reverência a divindades e pelos matrimônios: a fase das famílias, em que se formam essas primeiras formas de vida associativa, uma certa vida comunitária que, no entanto, ainda não é estatal. As famílias constituem, assim, um primeiro e pequeno esboço dos governos civis. Segundo Norberto Bobbio,

a fase das famílias, como etapa intermediária entre o estado bestial e o estado civil, é uma das inovações introduzidas por Vico na doutrina

\footnotetext{
${ }^{49}$ Ibidem, 681d. p. 148-149.

${ }^{50}$ Como admite Nicolini, in Vico, G. Princìi di Scienza Nuova, Mondadori, 1992, nota 1 do $\S 369$.
} 
dominante, tanto a que retoma a versão aristotélica (que vê o início da história da sociedade civil na família) como a da maior parte dos jusnaturalistas (para quem a história eterna ideal da humanidade se divide fundamentalmente em duas fases, a natural e a civil)51

Segundo Vico, depois da autoridade monástica vem a autoridade

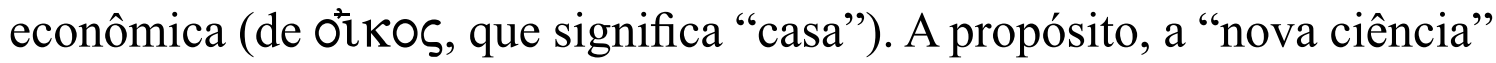
de Vico tem um princípio metodológico segundo o qual "le dottrine debbono cominciare da quando cominciano le materie che trattano". ${ }^{52}$ Por isso, a filosofia deve ser auxiliada pela filologia, e vice-versa. Assim, um dos dados filológicos que subsidiam a filosofia da história de Vico não é nada menos que a mesma imagem homérica dos ciclopes usada por Platão nas Leis para caracterizar o primeiro homem social da história, na qual o filósofo ateniense reconhece os primeiros pais da fase das famílias. ${ }^{53} \mathrm{~A}$ "nova ciência" é uma história do homem social, e como tal deve começar pela pesquisa dos primeiros homens das sociedades patriarcais: os ciclopes de Homero:

[...] há um lugar de ouro de Platão, ${ }^{54}$ segundo o qual, após os particulares dilúvios ogígico e deucaliônico, os homens habitaram as grutas sob os montes, e neles reconhece alhures os primeiros pais de família do mundo; depois, nos sopés, avista-os em Dárdano que construiu Pérgamo, que se tornou em seguida a cidadela de Tróia; finalmente, nas planícies, vislumbra-os em Ílio, pelo qual Tróia foi trazida junto ao mar e foi dita Ílio. ${ }^{55}$

A mudança do patriarcado para a aristocracia, em Platão e Vico, produz-se pela união dos chefes de família. Em Platão, essa união ocorre por três razões: o aumento da população, o desenvolvimento da agricultura

\footnotetext{
${ }^{51}$ Bobbio, N. A teoria das formas de governo, UNB, 2000. p. 121.

${ }^{52}$ Vico, G. Principi di Scienza Nuova, § 314.

${ }^{53}$ Ibidem, § 338.

${ }^{54}$ Platone. "Leggi”, 677-84. p. 144-151.

${ }^{55}$ Vico, G. Principi di Scienza Nuova, § 296.
} 
e a necessidade de proteção contra as feras. ${ }^{56}$ Em Vico, essa união devese à rebelião dos fâmulos. ${ }^{57}$ Esses, obrigados a viver permanentemente em estado servil, aborreciam-se com o correr do tempo, amotinando-se. A união dos chefes de família representa a primeira forma de organização civil, e assume a forma de uma república aristocrática, isto é, uma união de pais relativamente paritária. Para Vico, essa é a era dos heróis míticos; com eles, surge a primeira forma histórica de autoridade civil.

Uma teoria da história que reelabora elementos da teoria platônica e que exerce notável influência na filosofia da história de Vico é a de Políbio. Especialmente a teoria do ricorso e a descrição da fase terminal do corso histórico ressentem-se da exposição do fim da anaciclose (teoria dos ciclos) de Políbio. Com base no esquema de Heródoto das três formas de governo simples conforme o número de governantes (o governo de um, de poucos $\mathrm{e}$ de muitos), ${ }^{58}$ Políbio, seguindo de perto a tipologia do Político de Platão, ${ }^{59}$ desenvolve a teoria da alternância histórica de formas boas e suas formas correspondentes corrompidas. A partir do advento natural do governo do mais forte, a autocracia ( $\mu$ ov $\left.\alpha \rho \chi^{\prime} i \alpha\right)$, segue-se o governo aceito pela razão e justiça mais que pela força, o reino ( $\left.\beta \alpha \sigma \imath \lambda \varepsilon^{\prime} i \alpha\right)$, o qual com o passar das gerações se corrompe em tirania; essa provoca a tomada de poder de uma aristocracia de justos e sábios, os quais são sucedidos por descendentes pouco a pouco mais corrompidos, que passam a configurar uma oligarquia

\footnotetext{
${ }^{56}$ Platone. "Leggi”, 681a, p. 148-149.

57 Segundo Vico, os fâmulos são "esboços dos escravos, que logo em seguida chegaram com as capturas nas guerras", porque, inicialmente na condição de "ímpiosvagabundos-débeis", que levam uma vida selvagem e insociável, sendo os mais violentos mortos pelos pios e fortes pais de família, os mais fracos são acolhidos sob proteção na qualidade de fâmulos. Fugindo dos próprios males da vida ferina, esses bestioni recorrem, "para seu refúgio e salvação, às terras cultivadas pelos pios, castos, fortes e também poderosos, uma vez que esses estavam já unidos em sociedade de famílias" (§ 17-18). A relação entre os fâmulos e os pais de família não pode ser dita de escravidão, mas de clientelismo, já que os fâmulos se aproximam dos pais percebendo as conveniências dessa união. O termo "família" viria, segundo Vico, de "fâmulo", uma vez que aquela é constituída pelo conjunto do pai, filhos e fâmulos.

${ }^{58}$ Bobbio, N. Teoria das formas governo. p. 39-43.

${ }^{59}$ Platone, "Politico", in Tutte le Opere, Grandi Tascabili Economici Newton, 1997, 291d. p. 100-103; 302e. p. 123.
} 
de injustos e dissolutos; essa oligarquia dá lugar à revolução popular que institui a democracia, a qual, seguindo a análise de Platão, ${ }^{60}$ se corrompe e se transforma em demagogia, que Políbio chama de oclocracia, onde

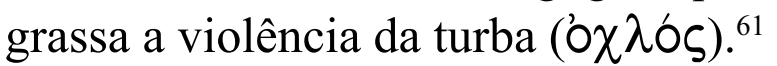

O critério de Políbio para distinguir a boa da má forma de governo é o mesmo do Político de Platão: o consenso e a violência, a legalidade e a ilegalidade. ${ }^{62}$ Outro elemento platônico que incide na análise das transformações históricas é a consideração de que a corrupção das formas de governo ocorre concomitantemente às mudanças e aos conflitos de gerações, ${ }^{63}$ e, assim como as gerações vindouras se transformam e adquirem suas características próprias a partir das condições deixadas pelas gerações dos progenitores, as formas de governo nascem e se desenvolvem naturalmente umas das outras. Tal como se dá no livro VIII da República de Platão, a corrupção tem um caráter natural e inevitável. Toda forma de governo tem em si o germe da sua corrupção, "como a ferrugem para o ferro, os carunchos e as cracas para a madeira"; 64 do reino, o mal congênito e correspondente é a autocracia; da aristocracia, a oligarquia; da democracia, a selvageria $(\theta \eta \rho \imath \omega \delta i \alpha)$ e o regime da força bruta $\left(\chi \varepsilon \imath \rho о \kappa \rho \alpha \tau^{\prime} i \alpha\right)$. Sábio é o legislador que, como Licurgo de Esparta, percebe que as mudanças ocorrem inevitavelmente pela própria natureza precária das formas de governo simples, e que calcula que toda forma de governo simples logo cai em rápida corrupção, pela qual se transforma no seu mal próprio e correspondente. A constituição de Licurgo contrabalança os princípios das formas de governo simples, reunindo as virtudes de cada uma, segundo a lei da compensação e do equilíbrio, de modo que o poder real $\left(\mathrm{B} \alpha \sigma \imath \lambda \varepsilon \varepsilon^{\prime} \alpha\right)$ se contém por temor do povo $(\delta \eta \hat{\mu} \mu \varsigma)$, e esse não despreza aquele por temor do conselho dos anciãos ( $\gamma \varepsilon \rho \circ v \sigma i \alpha)$, escolhidos entre os melhores

${ }^{60}$ Plato. The Republic of Plato, Cambridge, 1980, edited with critical notes, commentary and appendices by James Adam, VIII, 555b-566a. p. 229-255.

${ }^{61}$ Polybe. Histoires, Belles Lettres, 1977, VI, 5-9. p. 73-79.

${ }^{62}$ Ibidem, VI, 4, p. 71-72; cf. Platone, "Politico", 291e. p. 100-103.

${ }^{63}$ Ibidem, VI, 5-9, p. 73-79; cf. Plato. The Republic of Plato, 546a-573a, VIII-IX. p. 203-324; idem, "Leggi”, in Tutte le opere, Grandi Tascabili Newton, 1997, III, 695b. p. 172.

${ }^{64}$ Ibidem, VI, 10. p. 80. 
e mais justos cidadãos. Segundo Políbio, a fórmula do governo misto é a causa da longevidade da liberdade de Esparta e do sucesso de Roma ${ }^{65}$ Essa que é a principal tese da teoria polibiana das formas de governo, encontra em Platão um esboço no elogio - pelas mesmas razões de controle dos excessos - à constituição de Licurgo, com a diferença de que o equilíbrio aí se dá entre o poder real (já moderado pela divisão em duas estirpes reais), o conselho dos anciãos e os Éforos, que fiscalizam a atuação daqueles outros dois poderes. Compor um poder a partir de três é a causa da estabilidade e do sucesso de Esparta. ${ }^{66}$

Os ciclos de Políbio também começam por catástrofes naturais - ele menciona as perdas de colheitas, as epidemias e os supracitados

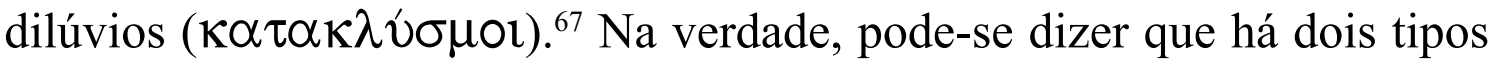
de ciclos: os grandes ciclos marcados por catástrofes naturais, que lançam os homens de tempos em tempos na completa indigência e na ameaça de extinção, com o destruição de todas as instituições e artes necessárias à vida humana; e os ciclos das formas de governo, que tem como causa a própria natureza humana e que recomeçam, ao que parece, independentemente das catástrofes. Dada uma condição inicial de completa indigência, tendo-se agrupado em decorrência de sua fragilidade natural, os homens vivem como

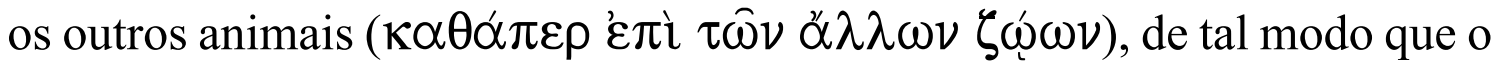
mais forte e audacioso lidera e comanda. Numa tal situação, onde o horizonte do poder é a força, os homens estão submetidos a uma certa autocracia $(\mu \circ v \alpha \rho \chi i \alpha)$. Essa é também a condição primitiva da humanidade: viver em grupos à maneira de animais e seguir os mais vigorosos e poderosos

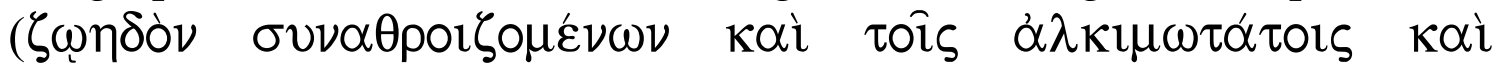

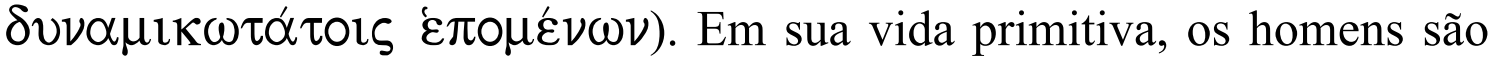
gregários como certos animais; não obstante, distinguindo-se dos outros animais por serem os únicos dotados de inteligência e raciocínio, percebem as noções de bem e de justo e o quanto são vantajosas, as quais reforçam a vida e os hábitos em comum ( $\sigma \nu \nu \tau \rho \circ \phi i ́ \alpha ~ \kappa \alpha i ̀ ~ \sigma \nu \nu \eta ́ \theta \varepsilon ı)$; assim, pouco a pouco os homens seguem e obedecem ao governante justo e reprovam o

\footnotetext{
${ }^{65}$ Ibidem, VI, 2, p. 68-69; 10. p. 81.

${ }^{66}$ Platone, "Leggi”, III, 691e-692c. p. 166-168.

${ }^{67}$ Polybe. Histoires, VI, 5. p. 73.
} 
injusto; a obediência deixa de ser por temor e passa a ser por aprovação do discernimento, sendo essa a passagem da autocracia ao reino. ${ }^{68}$

O fim da anaciclose guarda uma analogia com o início. Uma vez advinda a democracia, dá-se a sua corrupção: demagogos ávidos pelo poder incutem no povo a fome de vantagens e o tornam venal e devorador

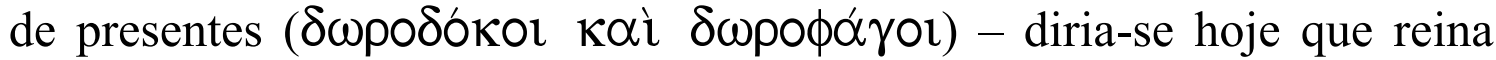
o fisiologismo. Estando assim as coisas, um líder ambicioso e ousado pode facilmente arrastar o povo para todo tipo de ilegalidade, e o povo, agrupando-se, realiza massacres, exílios, redistribui a terra, instituindo o império da força bruta ( $\chi \varepsilon ı$ เрокр $\alpha \tau \imath \alpha)$, até bestializar-se novamente ( $\alpha \pi \circ \tau \varepsilon \theta \eta p i \omega \mu \varepsilon \dot{\varepsilon} v 0 \nu)$, quando então encontra um senhor e autocrata

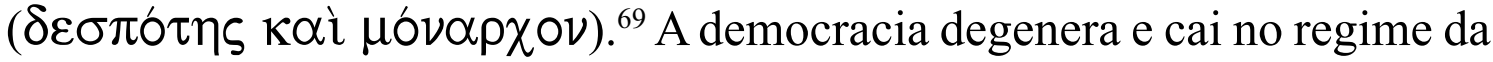

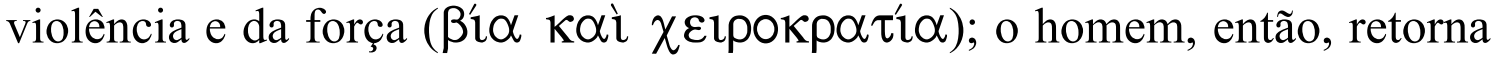
ao seu estado animal e se submete ao governo da força, a autocracia. Mas, o homem não retorna exatamente ao ponto de partida. O retorno à autocracia não significa um retrocesso à primitiva condição de indigência causada pela catástrofe natural. Os homens bestiais da oclocracia vivem cercados de artes e instituições. Talvez seja o caso de relevar uma nuança que permite distinguir a autocracia derivada da indigência que se segue à catástrofe natural e a autocracia resultante da degeneração da democracia:

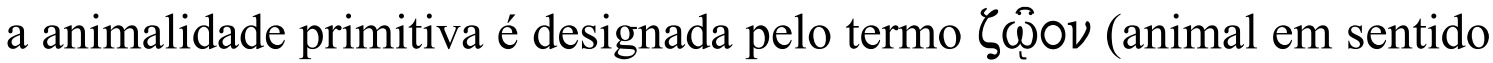
lato, vivente); já a bestialidade da turba enfurecida é representada pelo termo $\theta \eta p i ́ o v$ (fera, animal selvagem) ${ }^{70}$ o que pode sugerir que a animalidade primitiva é menos "desumana" do que a do final da anaciclose. O ciclo de Políbio vai, então, do animal selvagem que vive na natureza à fera urbana.

Platão não explica o que acontece no fim do ciclo, tampouco como se retorna ao ponto de partida, a não ser pela ocorrência, a intervalos longos, das catástrofes naturais. Políbio aponta, além das causas exóginas, causas endóginas, inerentes à natureza das coisas humanas, que produzem o reinício

${ }^{68}$ Ibidem, VI, 5-6. p. 73-75.

${ }^{69}$ Ibidem, VI, 9. p. 78-79.

${ }^{70}$ Esse é o termo usado por Aristóteles para designar o animal associal: "aquele que não pode viver em comunidade, nem precisa por causa da sua autosuficiência, não faz parte de qualquer cidade, e é uma fera (Oฤpíov) ou um deus"; cf. Aristóteles. Política, Vega, 1988, 1253a29. p. 54. 
do ciclo, mas não exatamente como num círculo fechado. Ele apenas afirma que a anaciclose das formas de governo é a economia da natureza, segundo a qual os governos mudam e se transformam e novamente chegam nas mesmas coisas..$^{71} \mathrm{O}$ fim do ciclo pode ser entendido simplesmente como análogo ao início, não idêntico. Essa teoria cíclica, assim considerada, não se deixa explicar completamente pela ideia de eterno retorno do mesmo. E assim, o movimento do ricorso de Vico torna-se muito mais inteligível pelo esquema cíclico de Políbio. A analogia entre o fim e o começo do ciclo pode, inclusive, ser empregada dentro de um esquema progressivo com um tempo criado, como é o caso da teoria de Vico. A anaciclose de Políbio é muito diferente do corso de Vico; entre outras coisas, aquela alterna boas e más formas de governo; esse tem um sentido progressivo: da pior à melhor forma de governo - a que ele considera melhor (o modelo é a monarquia de Augusto); não obstante, encontra-se em ambos a analogia entre o término do ciclo e seu início.

Em Vico há uma analogia entre o estado bestial primitivo e a barbárie da razão: ambos estão sob o signo da tirania do individualismo e da vida associal. ${ }^{72}$ Entretanto, a última consegue ser mais nefasta e violenta do que o primeiro. Veja-se a imagem extremamente sintética e vívida das causas da queda do Império Romano e da subsequente barbárie, situaçãolimite do primeiro corso histórico: ${ }^{73}$

\footnotetext{
${ }^{71}$ Polybe. Histoires, VI, 9. p. 79.

${ }^{72}$ Ao contrário de Políbio, para quem a comparação com a vida animal serve para descrever um tipo de vida gregária e social.

${ }^{73}$ A idade dos homens, ou idade da razão, é o ápice do desenvolvimento histórico da mentalidade humana, como se depreende do $\S 218$ ("os homens primeiro sentem sem se dar conta, depois se dão conta com ânimo perturbado e comovido, finalmente refletem com mente pura"). Mas ela tem em si o germe da sua corrupção, o que indica um movimento parabólico da história. Conforme os $§ 241-245$, dentro da idade da razão, os homens "deleitam-se com o prazer, depois se dissolvem no luxo e finalmente enlouquecem em destruir as coisas", de modo que a natureza racional é "benigna, depois delicada, finalmente dissoluta". À complexidade da idade da razão e seu movimento histórico parabólico correspondem os caráteres poéticos (os tipos) de célebres romanos: o valoroso e justo Cipião Africano; o repleto de glória, virtudes e vícios César; o triste reflexivo Tibério; finalmente, os furiosos, dissolutos e desavergonhados Calígula e Nero. Expressão e reforço da razão decadente é o que Vico
} 
Por tudo isso, com facções obstinadíssimas e guerras civis desesperadas, acabam fazendo selva das cidades, e das selvas covis de homens; e, desse modo, depois de longos séculos de barbárie, enferrujam-se as desgraçadas sutilezas dos engenhos maliciosos, que os haviam tornado feras mais cruéis com a barbárie da reflexão do que jamais havia sido a primeira barbárie do sentido. Porque aquela mostrava uma ferocidade generosa, da qual outros podiam se defender, ou sair vivos ou se resguardar; mas essa, com uma ferocidade vil, depois de lisonjas e abraços, prepara armadilhas à vida e à sorte de seus confidentes e amigos. Por isso, povos constituídos por essa reflexiva malícia, com tal último remédio que usa a Providência, tão aturdidos e estúpidos, não sentem mais confortos, delicadezas, prazeres e fausto, mas somente as necessárias utilidades da vida. ${ }^{74}$

chama de filosofia monástica, representada pela filosofia dos epicuristas e estóicos, muito difundidas na cultura romana do Império, as quais conduzem por vias diversas à negação da religião e da liberdade, ao ateísmo e ao abandono da vida ativa e da filosofia política. Ao mesmo tempo, a crítica à "barbárie da reflexão" também se dirige à própria época de Vico, e a passagem a seguir faz lembrar as cortes europeias de então, onde se cultivam como virtudes as elegâncias irônicas e a dissimulação. Do mesmo modo, as críticas de Vico às filosofias de alguns modernos são geralmente pautadas pela sua vinculação a esse ou aquele aspecto da filosofia monástica de epicuristas e estóicos.

${ }^{74}$ Vico, G. Pricipi di scienza nuova, § 1106: “... poiché tai popoli a guisa di bestie si erano accostumati di non ad altro pensare ch'alle particolari proprie utilità di ciascuno ed avevano dato nell'ultimo della dilicatezza o, per me' dir, dell'orgoglio, a guisa di fiere, che, nell'essere disgustate d'un pelo, si risentono e s'infieriscono, e sì, nella maggiore celebrità o folla de' corpi, vissero come bestie immani in una somma solitudine d'animi e di voleri, non potendovi appena due convenire, seguendo ogniun de'due il suo proprio piacere o capriccio -, per tutto ciò, com ostinatissime fazioni e disperate guerre civili, vadano a fare selve delle città, e delle selve covili d'uomini; e, 'n cotal guisa, dentro lungui secoli di barbarie vadano ad irruginire le malnate sottigliezze degl'ingegni maliziosi, che gli avevano resi fiere più immani com la barbarie della riflessione che non era stata la prima barbarie del senso. Perché quella scuopriva una fierezza generosa, dalla quale altri poteva difendersi o campare o guardarsi; ma questa, com una fierezza vile, dentro le lusingue e gli abbracci, insidia alla vita e alle fortune de' suoi confidenti ed amici. Perciò popoli di sì fatta riflessiva malizia, con tal ultimo rimedio, ch'adopera la provvedenza, così storditi e stupidi, non sentono più agi, dilicatezze, piacere e fasto, ma solamente le necessarie utilità della vita; e, nel poco numero degli uomini alfin rimasti e nella copia delle cose necessarie alla vita, divengano naturalmente comportevoli; e, per la ritornata primiera semplicità del primo mondo de' popoli, sieno religiosi, veraci e fidi; e così ritorni tra essi la pietà, 
A história não acaba aí. Findas as necessidades supérfluas do luxo e urgindo as necessidades vitais, a Providência faz com que os poucos homens sobreviventes das guerras se tornem naturalmente simples e tolerantes. Desse modo, poderiam retornar a piedade, a fé e a verdade, que, para Vico, "são os naturais fundamentos da justiça e são graças e belezas da ordem eterna de Deus". Note-se atuante a imagem polibiana da ferrugem, que representa a corrupção inerente à natureza humana. Além disso, Vico insere a condição da indigência, como fator de recomeço do ciclo, mas, desta vez, provocada pelas próprias guerras humanas, não por catástrofes.

A tese da função prática da história em Vico é claramente inspirada na reflexão de Políbio acerca da utilidade da história. A história oferece ao governante e ao legislador um conhecimento das causas da corrupção das instituições sociais. Pela observação das causas do sucesso e do insucesso de determinadas organizações sociais, é possível deliberar a melhor escolha em cada caso. Quem percebe como cada forma de governo surge e se desenvolve por força das circunstâncias é capaz de ver quando, como e onde o crescimento, a plenitude ( $\dot{\alpha} \kappa \mu \eta \dot{)}$ ), a transformação e o fim podem novamente ocorrer. O conhecimento da lógica dos ciclos permite saber em que ponto de desenvolvimento ou de decadência a nação está e seu futuro ponto de transformação, que certamente ocorrerá. Entregue à prudência dos governantes e legisladores, esse conhecimento pode servir para se

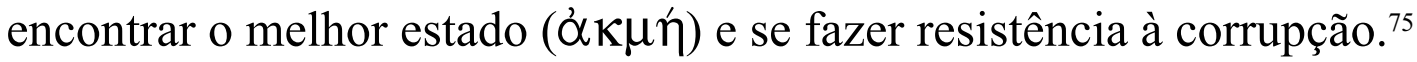

\section{Referências}

ARISTÓTELES. Política. Lisboa: Vega, 1988.

BOBBIO, N. A teoria das formas de governo. Brasília: UNB, 2000.

GUTHRIE, W.K.C. Os Sofistas. São Paulo: Paulus, 2007.

HESÍODO. Teogonia. São Paulo: Iluminuras, 1992.

. Os trabalhos e os dias. São Paulo: Iluminuras, 1996.

la fede, la verità, che sono i naturali fondamenti della giustizia e sono grazie e bellezze dell'ordine eterno di Dio".

${ }^{75}$ Ibidem, § 1405-6; cf. Polybe. Histoires, VI, 4. p.72; 9. p. 79-80. 
HOMERO. Odisseia. Porto Alegre: L\&PM, 2007.

LÖWITH, K. Significato e fine della storia. Milano: Comunità, 1979.

Pré- Socráticos. Os Pensadores. São Paulo: Abril, 1978.

PLATO. The Republic of Plato. Edited with critical notes, commentary and appendices by James Adam. Cambridge: Cambridge University Press, 1979, 1980.

PLATONE. Tutte le opera. Roma: Grandi Tascabili Economici Newton, 1997.

POLYBE. Histoires. Paris: Belles Lettres, 1977.

TERRA, R. Algumas Questões sobre a filosofia da história em Kant. In: KANT, Ideia de uma história universal de um ponto de vista cosmopolita. São Paulo: Brasiliense, 1986.

VICO, G. Opere Filosofiche. Firenze: Sansoni, 1971.

. Principi di Scienza Nuova. Milano: Mondadori, 1992.

Vidal-Naquet, P. La Démocratie Grecque vue d'ailleurs. Paris: Flammarion, 1990.

Data de registro: $12 / 05 / 09$

Data de aceite: 28/08/09 
